\title{
Impact of static and dynamic loads of vehicles on pavement
}

\author{
Elena Kurakina $^{1, *}$ and Sergey Evtiukov ${ }^{1}$ \\ ${ }^{1}$ Saint Petersburg State University of Architecture and Civil Engineering, 2 Krasnoarmeiskaya street, \\ 4, Saint Petersburg, 190005, Russia
}

\begin{abstract}
The present paper substantiates urgency of studies on early deterioration of pavement layers and on reasons entailing it. The aim was to investigate static and dynamic loads imposed on a road surface by vehicles in order to detect signs of early deterioration of pavement and understand its reasons. Certain tasks were set: to define diagnostic capacity for performing test works on road surface with the use of static and dynamic loading equipment; to carry out an elastic modulus analysis on the basis of static and dynamic loading tests performed; to assess strength properties of flexible pavement. The paper describes methods for determining strength properties of a road surface with the use of special static and dynamic loading equipment. The authors provide data on diagnostic capacity of tests of a pavement performed with the use of special testing equipment. The paper gives a list of potentials, advantages and fundamental features of the following units of equipment: apparatus for plate bearing tests, Dina-3M, UDN-NK, Dynatest apparatus. The main parameters of equipment for dynamic loading tests are provided. The results of both dynamic and static loading tests performed in Saint Petersburg and the Leningrad region are given. Deflection bowls and elastic modulus were determined. Coefficients of the dynamic elastic modulus being reduced to the static one were calculated. Strength properties of flexible pavement were assessed.
\end{abstract}

\section{Introduction}

Interaction between a vehicle and a road surface is one of the key factors of road safety. Currently, early deterioration of pavement layers and its reasons are relevant for studying. Within an operation period, road surface bears load from moving vehicles and is subjected to weather and climate impacts; these factors cause stress-strain state arising in layers. Static loads act longer than dynamic ones, so deformations under static loads reach their peak. Dynamic loads have short-term nature, an interval of their intensity depends on transportation and operation conditions (traffic intensity, vehicle class, axle loads, speed, total weight of a vehicle). The following authors carried out researches dedicated to this topic: Ph.D., professor E.V. Uglova, Ph.D. A.N. Titaturian, G.N. Kiryukhina. The authors of the present paper have assessed the state of flexible pavement on four road sections. The

* Corresponding author: elvl 86@mail.ru 
study helped to obtain values of variation coefficients for the examined road sections and to deduce that strength of the rigid structure is heterogeneous. The authors proved the need to diagnose road surfaces and determined the parameters of traffic flows with the use of a wide range of equipment for testing and diagnosing roads produced by the international company Dynatest [1,2]. Scientists E.R. Domke, S.A. Zhestkova obtained the results of studies on issues of reducing a number of traffic congestions and controlling traffic capacity of highways with taking into account characteristics of roads [3]. The issue of influence of the state of pavement surface on road safety was studied by such scientists as Pawer Rajczyk and Marcin Knapiński [4,5]. Motion of a vehicle causes vertical and horizontal stresses in a pavement that are decaying with depth due to material and resistance parameters of road layers. All impacts including temperature, moisture and drying initiate stresses and deformations of tension, shear, compression and torsion in a pavement, which consequently reduce its strength characteristics (Figures 1,2).

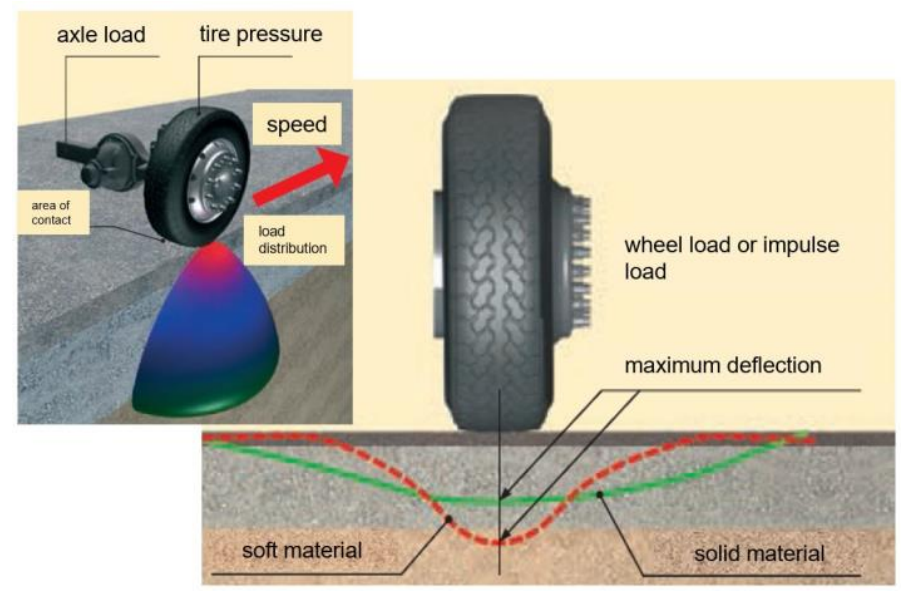

Fig. 1. Impact of a car wheel on pavement - "deflection bowls" of both rigid and flexible pavements in $3 \mathrm{D}$.

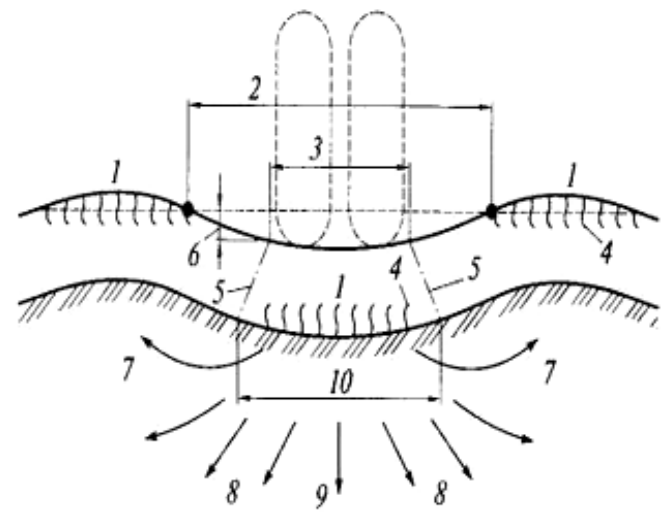

Fig. 2. Strain state of pavement: 1 - zone of tension; 2 - deflection bowl; 3 -zone of compression; 4 - cracks in pavement; 5 - cut surface of pavement; 6 - deformation of pavement; 7 - direction of soil extrusion; 8 - direction of soil compression; 9 - soil compaction in the road bed; 10 -area of pressure transfer to the ground.

Strength characteristics of a pavement depend on a "deflection bowl", which means the maximum permissible deflection value, as well as on the amount of load applied during a 
period of pavement weakening. During road operation, all deformations occur first without visual signs, so it is difficult to recognize them and anticipate their development. Thus, there is a need to control strength parameters of pavements.

\section{Materials and methods}

The authors applied methods of comparative analysis, theoretical, empirical and mathematical research methods for comparison, processing of data and for diagnostic studies. Dynamic and static loading methods for experimental research were used. The study involved the use of automated measuring, analytical and control engineering software and equipment: deflection indicator with software for performing field surveys, apparatus for a static plate bearing test, loading plate for performing static test, dynamic loading unit Dynatest used for evaluating the elastic modulus.

\section{Discussion}

Strength parameters of a pavement can be determined through the use of static and dynamic loading equipment. This method lies in assessing the bearing capacity of a pavement and determining an indicator of a common elastic modulus. The apparatus for plate bearing test consists of a loading plate (metal disk) with a cylindrical pier in the center and a loading device having a hydraulic pump and a counterweight of a vehicle (Figures 3.4).

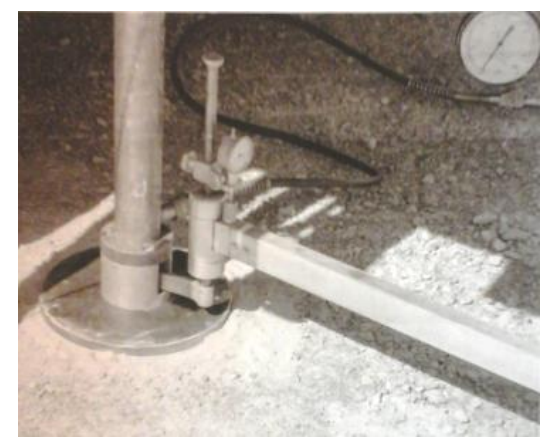

Fig. 3. General view of the loading plate for static tests.
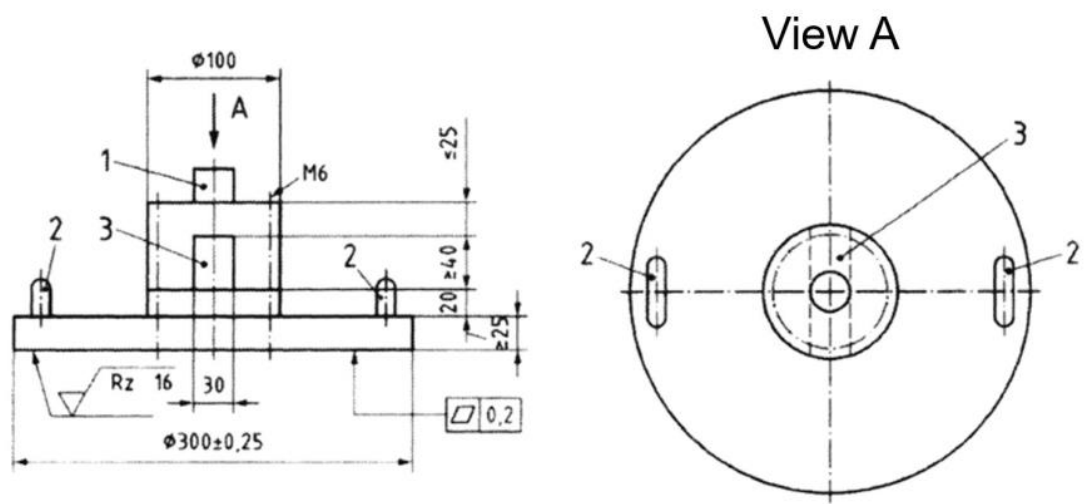

Fig. 4. Schematic diagram of a loading plate: 1 - centering pin with a rotatable head of hydraulic cylinder, 2 - handle for carrying a plate, 3 - tunnel for measurement, measurement admission is $+/$ $0.2 \mathrm{~mm}$. 
Process of testing is notable for obtaining measurements with a plate bearing test apparatus and determining a load plate settlement depending on an applied or removed load, according to which a graph is plotted containing a polynomial curve of general deformation during primary loading, unloading and a polynomial curve of elastic deformation during secondary loading (Road industrial methodical document ODM 218.5.007-2016 "Methodical recommendations for determining the elastic modulus with a static stamp").

Dynamic loading apparatuses are widely applied for assessing the elastic modulus (E). They can be used as trailers attached to mobile laboratories or to other vehicles. This equipment is used in Finland, Denmark, Sweden and the USA. Netherlands, Sweden and Denmark use dynamic loading apparatuses produced by Phoenix, Kuab. Dynatest apparatus is widely applied in Russia [6,7]. Testing facilities used in foreign countries, such as Dynatest 8000 FWD (performs measurements by analysis of falling weight deflection); 8000 VMD (deflection indicator installed in a van or minibus); 8081 HWD (performs measurements of elastic vibrations under the influence of a large weight load) satisfy the required conditions: the amplitude and duration of loading are identical to the impact of a heavy moving wheel, deformation measurements are highly accurate. General technical characteristics and the main components of the apparatus as well as the test results are presented in figures 5,6 .

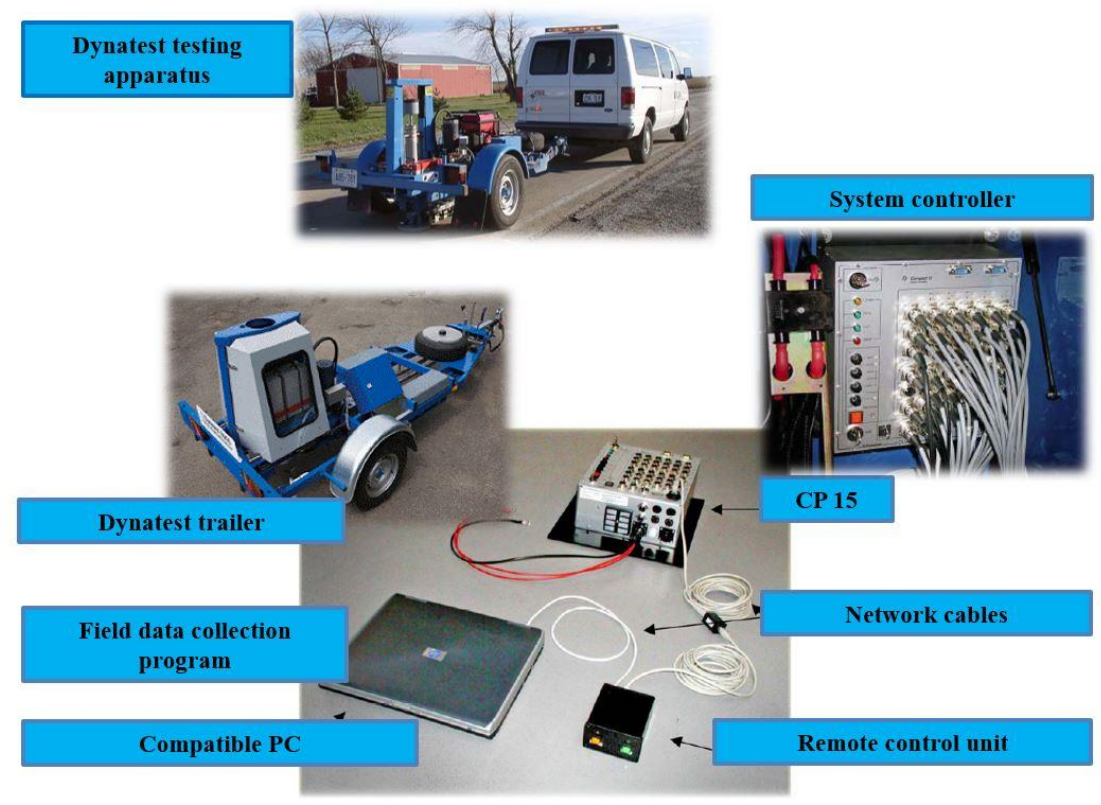

Fig. 5. General view of dynamic loading test apparatus Dynatest and its main components. 


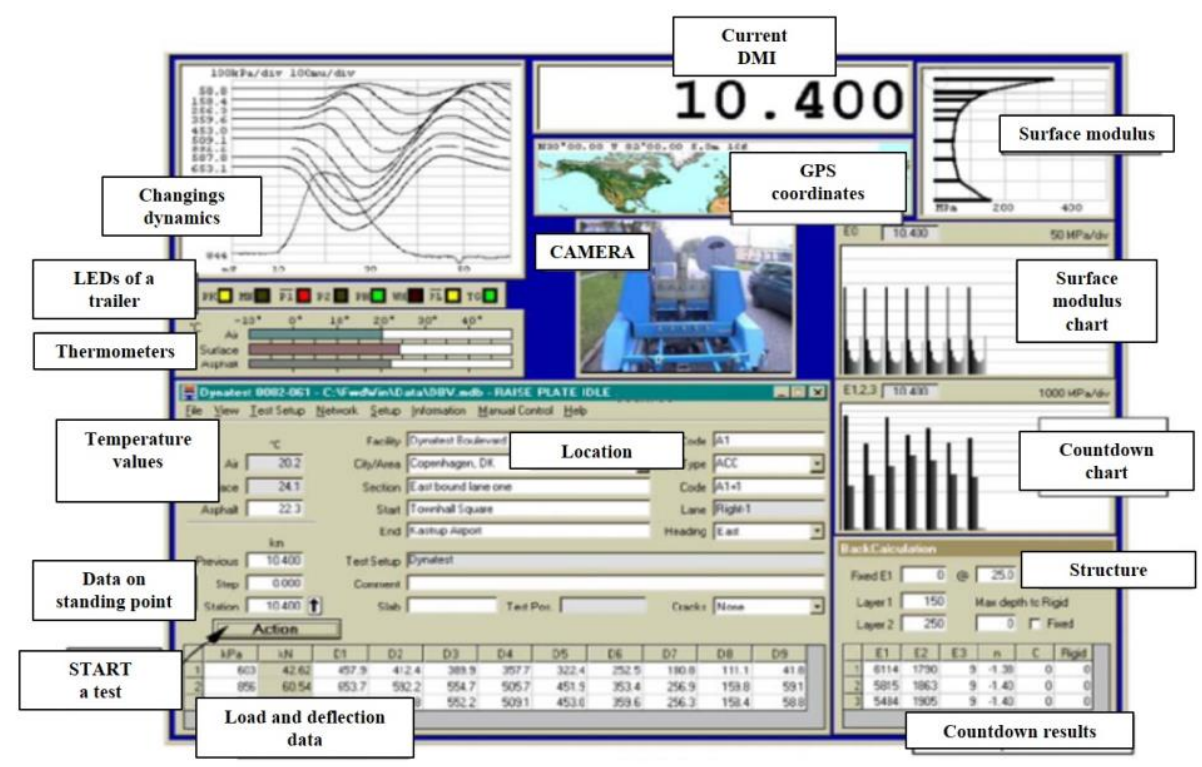

Fig. 6. Results of tests performed by dynamic loading apparatus Dynatest.

The use of automated software and equipment for measures, analytics and control - a deflection indicator with software - allows determining the deformation rate caused by a controlled loading on-site and with such accuracy, which is not available for other existing methods. In Russia, the diagnostics and assessment of roads' state, as well as determination of the elastic modulus (E) were carried out using Dina-3M and UDN-NK, which impose dynamic loads, and a long base lever-type deflection indicator imposing static loads [8]. The result of comparative analysis of the parameters of the dynamic loading apparatuses is presented in table 1 .

Table 1. The main setting parameters of dynamic loading apparatuses.

\begin{tabular}{|c|c|c|c|c|c|}
\hline $\begin{array}{c}\text { Type of } \\
\text { dynamic } \\
\text { loading } \\
\text { apparatus }\end{array}$ & $\begin{array}{c}\text { Height of } \\
\text { load } \\
\text { dropping, cm }\end{array}$ & $\begin{array}{c}\text { Weight } \\
\text { of load, } \\
\mathrm{kg}\end{array}$ & Contact time, $\mathrm{s}$ & $\begin{array}{c}\text { Plate } \\
\text { diameter, } \\
\mathrm{cm}\end{array}$ & Impulse of loading \\
\hline Dina-3M & 51 & 160 & 0.03 & 33 & Sinusoidal \\
\hline UDK-3 & up to 150 & 40 & 0.03 & 34 & Triangular \\
\hline $\begin{array}{c}\text { Dynatest } \\
\text { FWD }\end{array}$ & 45 & 235 & 0.03 & 33 & Semi-sinusoidal \\
\hline
\end{tabular}

The analysis of technical characteristics of the equipment chosen for comparison enabled determining the elastic modulus. The advantages of Dynatest apparatus are a high accuracy of simulating a load from a moving car wheel imposed on a pavement and a short time of determination of the following parameters: state of a pavement structure; layer-bylayer determination of the elastic modulus of the whole structure and particular layers; bearing capacity of a pavement and estimated residual life of a top layer; modeling of "weak" road sections that increas chances for traffic collisions $[6,7,9,10]$.

The main strengths of the dynamic loading apparatus Dynatest are the following: during the correlation process, the impact on values of both peak loads and elastic vibrations coming from possible undesirable high frequency components is minimized in the load 
cycle; Dynatest software has a peak smoothing function; Dynatest apparatus measures the temperature on the surface of a pavement, in upper layers and the environment [10,11-13].

\section{Results}

Dynamic and static loading tests were performed in St. Petersburg and the Leningrad region $[6,7,10]$, taking into account Road industrial methodical document ODM 218.5.007-2016. "Methodological recommendations for determining the elastic modulus with the use of an apparatus for static plate bearing test".

The obtained data on elastic deflection of a pavement are presented on the graph (Figure 7). The temperature of the upper layers during testing was $19.8 \div 22.6^{\circ} \mathrm{C}$, of the surface $20.7 \div 26.7^{\circ} \mathrm{C}$, of the air $-18.8 \div 22.7^{\circ} \mathrm{C}$.

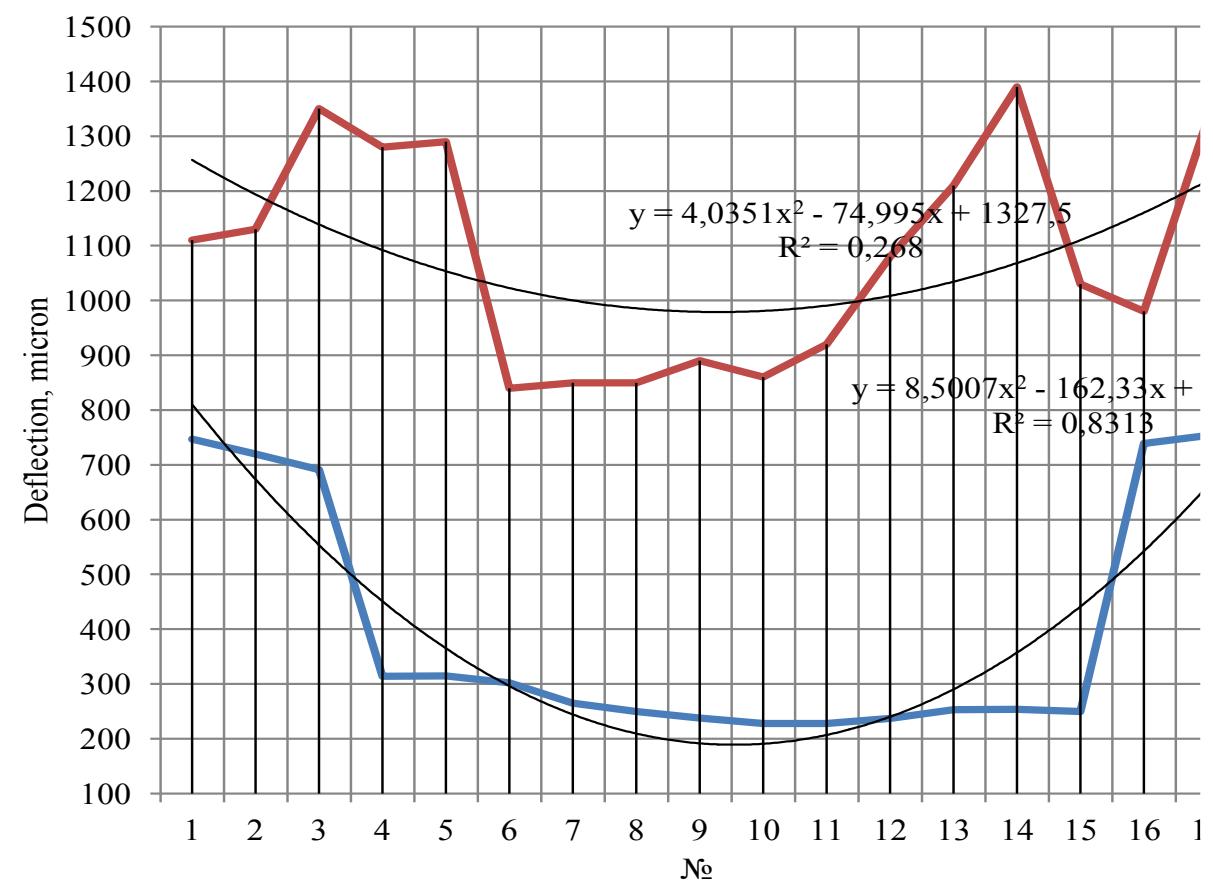

Fig. 7. Results of dynamic and static loading tests: a) - deflection of pavement under static load imposed by apparatus; $b$ ) - deflection of pavement under dynamic load imposed by Dynatest apparatus.

Simultaneous application of static and dynamic loading methods implies that results should be drawn up according to ODN 218.1.052-2002 "Strength assessment of flexible pavement", MODN 2-2001 "Design of flexible pavement:

$$
l_{a}=\left(X_{2} \cdot l_{D}\right)+X_{1},
$$

where $X_{1}$ and $X_{2}$ are empirical coefficients of regression dependence; $l_{\mathrm{a}}$ is the actual deflection of a structure on a distinctive section that corresponds to the permissible 
percentage of deformed surface of a pavement (estimated reliability of a pavement), under static application of a design load; $l_{\mathrm{D}}$ is the same under short-term loading.

Taking into account formula 1 and the obtained test results, the output data are obtained for defining the coefficient of reducing the dynamic elastic modulus (E) to the static one, taking into account Road industrial methodical document ODM 218.3.072 - 2016 "Methodological recommendations for determining the residual life of the bearing capacity of non-rigid pavements and elastic moduli of structural layers (table 2).

Table 2. Reducing dynamic modulus to static modulus.

\begin{tabular}{|c|c|c|c|}
\hline \multicolumn{2}{|c|}{ Common elastic modulus, $\mathrm{E}_{\text {com }}, \mathrm{MPa}$} & \multirow[b]{2}{*}{$\begin{array}{c}\text { Reduction coefficient of } \\
\text { common elastic } \\
\text { modules, } X_{i}=E_{D} / E_{C}\end{array}$} & \multirow[b]{2}{*}{$\begin{array}{c}\text { Mean-square } \\
\text { error }\end{array}$} \\
\hline $\begin{array}{l}\text { Elastic modulus in } \\
\text { terms of dynamic } \\
\text { tests, } E_{D}\end{array}$ & $\begin{array}{c}\text { Elastic modulus in } \\
\text { terms of dynamic tests, } \\
E_{C} \\
\end{array}$ & & \\
\hline \multicolumn{4}{|c|}{ Crushed gravel and gravel-sand layers } \\
\hline 206.6 & 261.0 & 0.79 & 0.0081 \\
\hline 216.3 & 246.0 & 0.88 & 0.0000 \\
\hline 210.5 & 213.0 & 0.98 & 0.01 \\
\hline & av & 0.88 & \\
\hline \multicolumn{3}{|c|}{ Mean-square error } & 0.06 \\
\hline & Mean-square error, $\%$ & & 5.82 \\
\hline \multicolumn{4}{|c|}{ Lightened type, asphalt concrete pavement } \\
\hline 501.3 & 327.0 & 1.53 & 0.0064 \\
\hline 500.5 & 336.0 & 1.49 & 0.0144 \\
\hline 522.3 & 365.0 & 1.43 & 0.0324 \\
\hline 535.8 & 266.0 & 2.01 & 1.96 \\
\hline \multicolumn{2}{|c|}{$\mathrm{X}_{\mathrm{av}}$} & 1.61 & \\
\hline \multicolumn{3}{|c|}{ Mean-square error } & 1,14 \\
\hline & Mean-square error, $\%$ & & 3.44 \\
\hline \multicolumn{4}{|c|}{ Permanent type, asphalt concrete pavement } \\
\hline 598.2 & 345.0 & 1.73 & 0.0031 \\
\hline 632.2 & 336.0 & 1.88 & 0.0084 \\
\hline 693.6 & 345.0 & 2.01 & 0.0486 \\
\hline 691.3 & 399.0 & 1.73 & 0.0033 \\
\hline 623.8 & 355.0 & 1.76 & 0.0011 \\
\hline 623.3 & 399.0 & 1.56 & 0.0518 \\
\hline 633.8 & 345.0 & 1.84 & 0.0022 \\
\hline & $\mathrm{Kav}$ & 1.79 & \\
\hline \multicolumn{3}{|c|}{ Mean-square error } & 0.13 \\
\hline \multicolumn{3}{|c|}{ Mean-square error, $\%$} & 7.28 \\
\hline
\end{tabular}

According to calculation results, the ratio of dynamic modules to static modulus obtained on gravel and gravel-sand layers is 1, on lightened asphalt concrete pavement is 1.6 , on permanent pavement is almost 2 .

\section{Conclusions}

Diagnostic assessment of static and dynamic loads' impact on a pavement have proved the necessity to use modern equipment, which is selected proceeding from such aspects as safety of technological measurement processes, convenience, swiftness of information receiving and processing, ability to analyze the entire spectrum of parameters under study. The deflection under static loading is greater than under dynamic one, since the impact of the first is significantly longer. Under a short-term dynamic loading, there is a greater value 
of the elastic modulus that characterizes the ability to undergo elastic deformations under loads imposed.

\section{References}

1. A.N. Tiraturyan, E.V. Uglova, A.A. Lyapin, PNRPU Mechanics Bulletin 2, 178-194 (2017) DOI 10.15593/perm.mech/2017.2.10

2. A.N. Tiraturyan, E.V. Uglova, 27TH Russian-Polish-Slovak seminar, theoretical foundation of civil engineering (27RSP). TFOCE 2018/Rostov-on-Don (2018) DOI: 10.1051/matecconf $/ 201819601020$

3. V.V. Akulov, A.N. Tiraturyan, et al., Russian journal of transport engineering 4(5) (2018) DOI: 10.15862/20SATS418.

4. P. Rajczyk, E. Kurakina, M. Knapiński, Transportation Research Procedia 36, 640-648 (2018) doi.org/10.1016/j.trpro.2018.12.139

5. S. Evtiukov, E. Kurakina, et al., Transportation Research Procedia 20, 185-192 (2017) DOI: 10.1016/j.trpro.2017.01.049

6. E. Kurakina, S. Evtiukov, J. Rajczyk, Transportation Research Procedia 36, 380-385 (2018) DOI:10.1016/j.trpro.2018.12.111

7. V. Kapitanov, V. Silyanov, et al., Transportation Research Procedia 36, 252-259 (2018) doi.org/10.1016/j.trpro.2018.12.077

8. S.S. Yevtyukov, Ye.V. Golov, Transport Urala № 2 (53), 85-89 (2017) DOI: 10.20291/1815-9400-2017-2-85-89

9. S. Evtiukov, E. Golov, G. Ginzburg, Transportation Research Procedia, pp.157-165 (2018) DOI: 10.1016/j.trpro.2018.12.058

10. Ye.V. Kurakina, Vestnik grazhdanskikh inzhenerov SPbGASU №2(67), 231-237 (2018) DOI: 10.23968/1999-5571-2018-15-2-231-23

11. S. Evtukov, E. Golov, T. Sazonova, MATEC Web of Conferences, 04018 (2018) DOI: $10.1051 /$ matecconf $/ 201823904018$

12. P. Kravchenko, E. Oleshchenko, Transportation Research Procedia 20, 367-372 (2017) doi.org/10.1016/j.trpro.2017.01.051

13. The Effect of Sun Glare: Concept, Characteristics, Classification. Research Procedia 20, 474-479 (WoS , Scopus 2017) doi.org/10.1016/j.trpro.2017.01.077 